\title{
CONSTRUYENDO LA CAPACIDAD DE APRENDIZAJE ORGANIZATIVO DESDE LA PERSPECTIVA DEL CONOCIMIENTO
}

\author{
Mario Villar Vargas, Luis Araya-Castillo y Esmeralda Giraldo Casado
}

\section{RESUMEN}

El aprendizaje organizativo es un concepto relativamente reciente y cuyo significado es motivo de intensa discusión teórica. Basado en esto, el objetivo de este trabajo es establecer los elementos fundamentales del concepto de aprendizaje colectivo desde la perspectiva del conocimiento, de tal manera de dimensionar las condiciones que lo favorezcan y, por tanto, faciliten el logro de los resultados organizativos. La metodología utilizada fue la revisión teórica de la literatura existente acerca del aprendizaje organizativo configurando los aportes de diversos autores desde la perspectiva del conocimiento. Los resultados obtenidos fueron la definición de un constructo del aprendizaje colectivo desde la perspectiva del conocimiento que puede ser testeado para efectos de dimensionar la capacidad de aprendizaje colectivo de una firma. Si bien el aprendizaje organizativo puede estudiarse desde tres perspectivas: desde la perspectiva del cambio, desde la perspectiva del conocimiento y considerando ambas perspectivas. La perspectiva del conocimiento adquiere especial relevancia puesto que el conocimiento se ha constituido como un factor de producción y de diferenciación estratégica cu yo valor está precisamente en la capacidad de contribuir a la ventaja competitiva.

Palabras Clave: Aprendizaje Organizativo, Perspectiva del Cambio, Perspectiva del Conocimiento, Constructo.

DOI: $10.23881 /$ idupbo.018.2-7e 